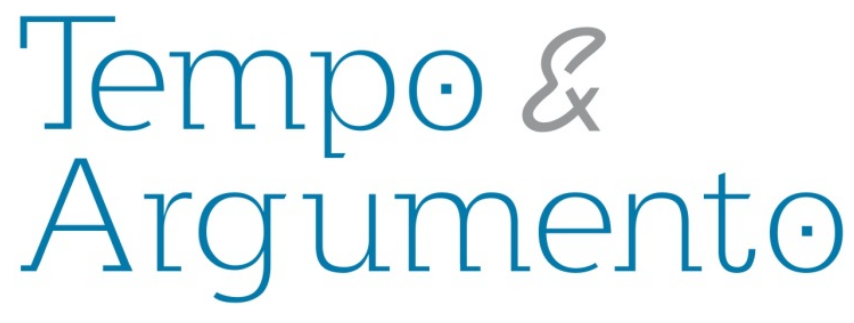

\title{
História do Tempo Presente e América Latina: Argentina - uma entrevista com María Inés Mudrovcic
}

\section{Entrevistada \\ María Inés Mudrovcic es doctora en filosofía por la Universidad de buenos aires, profesora titular de filosofía de la historia en la Universidad Nacional del Comahue e investigadora del CONICET y categoría I en el Programa Nacional de Incentivos. Actualmente es Directora del Centro de Investigaciones en Filosofía de las Ciencias Sociales y Humanidades y miembro del Consejo Directivo del Instituto Patagónico de Estudios en Humanidades y Ciencias Sociales. $\mathrm{Ha}$ sido profesora invitada en numerosas universidades nacionales e internacionales. $\mathrm{Ha}$ escrito Voltaire, el lluminismo y la Historia (Buenoa Aires, Fundec, 1996), Historia, Narración y Memoria. Los debates actuales en filosofía de la historia (Madrid, Akal, 2005), como editora, Pasados recientes en conflicto. Representación, mito y política (Buenos Aires, Prometeo, 2009) y en co-autoría, En busca del tiempo pasado. Temporalidad, historia y memoria (México, Siglo XXI, 2013). Asimismo ha escrito artículos y capítulos de libro sobre teoría y filosofía de la historia}

\section{Entrevistadoras}

\author{
Camila Serafim Daminelli \\ Doutoranda no Programa de Pós- \\ Graduação em História da Universidade \\ do Estado de Santa Catarina. \\ Brasil \\ camis.hst@gmail.com
}

\author{
Elisangela da Silva Machieski \\ Doutoranda no Programa de Pós- \\ Graduação em História da Universidade \\ do Estado de Santa Catarina. \\ Brasil \\ lismachieski@gmail.com
}

Entrevista concedida em agosto de 2017.

\section{Para citar esta entrevista:}

MUDROVCIC, María Inés. História do Tempo Presente e América Latina: Argentina - uma entrevista com María Inés Mudrovcic. [Entrevista realizada em agosto, 2017]. Revista Tempo e Argumento, Florianópolis, v. 9, n. 21, p. 450 - 471, maio/ago. 2017. Entrevistadoras: Camila Serafim Daminelli e Elisangela da Silva Machieski.

\section{DOI: $10.5965 / 2175180309212017450$}

http://dx.doi.org/10.5965/2175180309212017450 
Tempo e Argumento: ¿Cuál fue su trayectoria académica desde el inicio de sus estudios universitarios?

María Inés Mudrovcic: Soy Profesora y Licenciada en Filosofía y obtuve el título de Doctora en Filosofía en el año 1994. Todos los estúdios los realicé en la Universidad de Buenos Aires (UBA). Mi tesis doctoral se tituló "Voltaire, el lluminismo y la Historia" y la escribí siendo becaria del Conicet. ${ }^{1}$ Fueron años en los que también leí a Bayle, Bossuet, Montesquieu. Descubrí al Hume historiador, "el alumno de Voltaire" y al "Tácito de los ingleses", como era considerado en su época. Fue la primera vez que me enfrenté a una historia, en este caso, la historia de la filosofia moderna que había aprendido en la Facultad, que me había "ocultado" una faceta muy importante de Hume y me había enseñado sólo al Hume del Treatise o del Essay. Encontré la Enciclopedia, una segunda edición, un incunable, que guardaba la biblioteca de la Facultad de Filosofia y Letras. Fue una época de devorar autores franceses e ingleses del siglo XVII y XVIII. Inicio mis atividades docentes en la Universidad Nacional del Comahue, primero como ayudante y actualmente como Profesora Titular Regular de Filosofía de la Historia. Tuve la suerte de trabajar en la carrera de Historia y entrar en contacto directo con docentes y alumnos de historia, desde mis inicios en 1991. Tanto la Licenciatura como el Profesorado de Historia de la Universidad del Comahue tienen un área de Teoría de la Historia muy robusta, es decir, cuentan con asignaturas como Teoria de la historia, Metodología, Filosofía de la Historia, Introducción, etc. Cuando comienza, en el año 1997, el Profesorado y la Licenciatura en Filosofía, también ingresé enseñando Filosofía de la Historia. Elaboré el proyecto y participé de la creación de la Revista Páginas de Filosofía de la Facultad de Humanidades de la Universidad Nacional del Comahue de la que fui su Directora desde 1991-1995. Paralelamente comencé a dirigir proyectos de investigación siempre enfocados a problemas teóricos y filosóficos de la historia. El primero hizo foco en la cuestión de las formas discursivas de representar al pasado y, a partir del año 2000, comencé a trabajar cuestiones puntuales de temporalidade, historia y

\footnotetext{
${ }^{1}$ CONICET es la sigla del Consejo Nacional de Investigaciones Científicas y Técnicas, principal entidad de fomento a la investigación en Argentina.
} 
memoria. También dirigí proyectos Conicet y Foncyt ${ }^{2}$ y participé y dirigí proyectos internacionales, principalmente en México, por las relaciones entre Conicet y Conacyt y en Francia a través del CNRS $^{3}$ y Conicet. En 2000, un grupo de docentesinvestigadores creamos el Centro de Investigación en Filosofia de las Ciencias Sociales y Humanidades del que soy su Directora y que fue y es sede de todos los proyectos que dirijo en la Universidad del Comahue. Desde 2005 soy Investigadora del Conicet y desde el año pasado soy miembro del Consejo Directivo del Instituto Patagónico de Estúdios en Ciencias Sociales y Humanidades (Conicet-Unco). Instituto creado en 2016 y en cuyo proyecto participé. Desde el Centro de Investigación organizo, desde hace años, junto a colegas, becarios y alumnos, reuniones a las que asisten investigadores tanto del país como del exterior (Simposio Internacional "La reflexión histórica en las disciplinas humanas y en las prácticas sociales"1997, Jornadas de Investigación: "La relación historia-memoria" 2000, XII Congreso Nacional de Filosofía organizado por la Asociación Filosófica Argentina 2003, I Jornadas Nacionales de Filosofía y Epistemología de la Historia "Problemas de representación del pasado reciente" 2007, II Jornadas Nacionales de Filosofía y Epistemología de la Historia "Tiempo de la historia y tiempo de la memoria: los usos políticos del pasado" 2011 y, ahora estamos organizando las III Jornadas que se llevarán a cabo en 2018). Me han invitado y he participado de muchísimas reuniones nacionales e internacionales en los que conocí a colegas ocupados com mis mismas preocupaciones teóricas y alumnos ávidos de preguntas. En fin, me es difícil hablar de mí misma. Si tuviese que destacar algo, es a la gente que formo y he formado, los colegas que he conocido y conozco y los libros y artículos publicados que me han permitido llegar a lugares inimaginables.

\footnotetext{
${ }^{2}$ La Agencia Nacional de Promoción Científica y Tecnológica de Argentina mantiene el Foncyt, Fondo para la Investigación Científica y Tecnológica.

${ }^{3}$ Se trata del Centre Nacional de la Recherche Scientifique (Centro Nacional de Investigación Científica de França).
} 
Tempo e Argumento: ¿Cómo podría situar su producción académica dentro del escenario historiográfico de Argentina?

María Inés Mudrovcic: No escribo historia, escribo sobre la historia. Es decir, no hago historiografia, sino filosofia y teoria de la historia. Mi producción académica se ubica más en torno a la teoria y metodologia de la historia. Siempre partí de la convicción que de toda "filosofia de la......" no debe ser prescriptiva, de allí mi profunda interacción con los historiadores.

Tempo e Argumento: Actualmente, ¿cuáles son los enfoques de sus trabajos?

María Inés Mudrovcic: Dos son los ejes de mis trabajos actualmente, continúo en primer lugar, con el tema del tiempo centrado, ahora, en el presente pero desde un enfoque performativo y, en segundo lugar, estoy analizando de qué modo se están re-escribiendo las fronteras disciplinares en lo que va del siglo XXI.

El presente comienza a ser fuertemente teorizado a partir del nacimiento de la Historia del Presente. Aún cuando la noción de presente siempre estuvo implicada en el hacer historiográfico y es el punto ciego de la historia, no es sino hasta hace muy poco que comienza a tener un lugar central, sobre todo en la reflexión filosófica y teórica sobre la historia. Pensemos, por ejemplo, en el clásico libro de R. Koselleck, Futuro Pasado, en el que las dos categorias centrales son "espacio de experiência" y "horizonte de expectativas" y el presente parece reducirse a una simple intersección o articulación entre ambas, sin densidade alguna. Es difícil asir el presente. En la actualidad, y en ese esfuerzo por tratar de darle un contorno a lo que entendemos por presente, no lo pienso como algo que experimentamos pasivamente, ya sea como aceleración o como omnipresencia, sino como resultado de actos que realizamos con el tiempo. Parafraseando a J. Austin, la idea es pensar cómo hacemos cosas con el tiempo, a esa operación sobre el tiempo yo la denomino "políticas del tiempo". Las políticas del tiempo cualifican al pasado, al 
presente y al futuro. Un tiempo cronológico, meramente cuantitativo, que se constituya en parámetro desinteresado y objetivo de las actividades humanas es impensable y, aun cuando lo fuese, sería resultado de lo que aquí denomino “políticas del tiempo". El término “política” no debe ser entendido como sinónimo de ideología o de valores políticos, sino como una forma de autoridad que, en el caso específico del tiempo, determina qué o quiénes pertenecen al presente. Las políticas del tiempo consisten en un conjunto de operaciones que, a la vez que sancionan lo que es propio o característico del presente, construyen un "otro" excluyéndolo diacrónica o sincrónicamente de ese presente, el otro es anacrónico. Voy a citar dos ejemplos: el 10 de diciembre de 2016 el gobierno argentino crea el Ministerio de Modernización el que, entre otras cuestiones, se propone "Diseñar, proponer y coordinar las políticas de transformación y modernización del Estado". Su ministro acaba de expresar, hace pocos días atrás, que habían recibido un estado "arcaico", propio del "siglo XIX". El científico inglés Richard Dawkins en una columna que publicara el diario El País el 6 de abril del corriente año confiesa abiertamente el "desprecio" que le provoca "la mezquindad moral, espiritual, política e intelectual de los británicos que votaron a favor del Brexit en el referéndum" (2015). En un intento de explicación cuasi freudiano, Dawkins atribuye el voto pro Brexit, de los que él denomina "gerontobrexiteros", a la nostalgia de la “juventud perdida". 4 Es así que, en Argentina, un estado "moderno" (la “modernidad" se encarna en una institución) se erige frente al estado "obsoleto y arcaico" heredado del pasado. La arena política simplifica generacionalmente el resultado expulsando del presente a los votantes pro Bexit como "viejos" nostálgicos. Aun cuando todos los votantes del Brexit vivan en un mismo presente cronológico, no todos "pertenecen" al mismo: los que votaron a favor son los “gerontes del pasado". Según funcionarios del gobierno argentino, la estructura del Estado actual no es la adecuada para el presente "moderno". Creo que enfocar el estúdio del presente desde esta perspectiva performativa nos ayuda a entender de

\footnotetext{
${ }^{4}$ Ver: http://elpais.com/elpais/2017/04/02/opinion/1491143414_963850.html.
} 
qué modo nosotros creamos nuestros presentes y decidimos quiénes los habitan y quiénes, no.

También estoy siguiendo los debates que se dan en torno a las fronteras disciplinares y que propician una visión transversal de los saberes, en especial, de la historia y las ciências sociales. No nos olvidemos que la economia, la historia, la antropologia, la psicologia son todas “hijas" del siglo XIX. La historia nace desmarcándose fuertemente de la literatura, estableciendo su objeto en el pasado y dejando el presente para antropólogos y periodistas. El nuevo acercamiento a la literatura o al periodismo que proponen historiadores como I. Jablonka (la "historia es una literatura contemporánea") o F. Dosse están en las antípodas de lo que pensaba, por ejemplo, J. Huizinga en 1931: el pasado y sus "formas definidas" son propios de la historia, el presente es para los diários. Vivimos en una época en la que los historiadores se "manifiestan”, Manifestos for History (K. Jenkins, S. Morgan y A. Munslow), el de I. Jablonka por las ciências sociales, el The History Manifesto (J. Guldi y D. Armitage). Como dijo H. White, el manifesto es un género radical, cuyo tiempo es el presente y presupone un tiempo de crisis. ¿Por qué los historiadores se sienten obligados a legislar qué deberán escribir los historiadores del futuro?. "La historia há estalado en migajas", esta frase de F. Dosse quizás resuma de qué modo la pluralidade epistémica de la disciplina histórica está obligando a repensar sus limites disciplinares.

Tempo e Argumento: ¿Cómo la Historia del Tiempo Presente se volvió una preocupación en su carrera? ¿Cuáles fueron las referencias teórico-metodológicas que le influenciaron en su proyecto de historizar el "tiempo presente"?

María Inés Mudrovcic: Creo que se conjugaron varias razones. En primer lugar, influyó mi interés teórico en los tiempos de la historia y la función social del historiador y mi gusto por la lectura de historiadores contemporáneos. En segundo lugar, una relación muy estimulante $y$, en algunos casos de amistad, con filósofos, historiadores, cientistas sociales e intelectuales que habían sido contemporáneos 
del pasado reciente dictatorial y han sido y son actores muy comprometidos com el presente argentino: José Sazbón, Nora Rabotnikof, Hugo Vezzetti, José Emilio Burucúa, Eduardo Rabossi, Claudio Ingerflom. Tuve la fortuna de conocer a José Sazbón y poder trabajar a su lado. Hasta 2008, año en que murió, mis viajes a Buenos Aires no estaban completos si no había compartido un café con José en su estúdio. Era realmente un sábio humanista ardiente, como lo llamó un colega, erudito, profundo, modesto. Exiliado durante la Dictadura, a su regreso enseñó Filosofía y Teoría de la Historia, e Historia de las Ideas y hasta su muerte coordinó la Maestría de Historia y Memoria de la Universidad Nacional de La Plata, en la que trabajé. Nora Rabotnikof es la que me acompanha en esta etapa. También atravesada por el exilio, pero esta vez en México. Desde la filosofía política piensa presentes y pasados tan disimiles como Argentina y México, con ella tenemos vários proyectos en común y hemos coordinado juntas un libro. ${ }^{5}$ De todos ellos he aprendido y sigo aprendiendo, todos ellos han sido siempre muy generosos conmigo. Por último, influyó el momento en que ingresé como investigadora en la Universidad, pues me tocó transitar un presente político en el que el boom memorial estaba en su apogeo y que influyó, sin duda alguna, en mi producción académica. En 1999, durante la realización de las VII Jornadas Interescuelas/Departamentos de Historia en la Universidad del Comahue, conozco a Julio Aróstegui, uno de los fundadores de la Hispanianova. Revista de Historia Contemporánea, (España) quien me propone publicar mi trabajo "Algunas consideraciones epistemológicas para una "Historia del Presente"”, en el primer número de la revista. En ese momento, a más de 20 años del Golpe Militar asistíamos al auge memorial en Argentina. Para ese entonces, ya se había producido el Historikerstreit y el debate Goldhagen en Alemania, y faltaba muy poco para que Jan Tomasz Gross publicara su libro sobre la masacre de Jedwabne (Neighbors. The destruction of the Jewish community in Jedwabne, Poland, 2001) y provocara el pedido de perdón público del presidente polaco Aleksander Kwaśniewski a las víctimas y sus familiares, y el historiador Hilberg ya había testificada en el caso

\footnotetext{
${ }^{5}$ En busca del tiempo perdido. Temporalidad, historia y memoria, México: Siglo XXI, 2013.
} 
Zündel, en el que el escritor Irving participó de la defensa. Todos constituían, para mi, claros ejemplos no sólo de la incidencia directa en la esfera pública de la investigación histórica, sino también de la relación directa entre un contexto democrático y la posibilidad misma de una Historia del Presente. En mi país, sin embargo, existía un fuerte debate entre los historiadores de la "academia" que seguían insistiendo en la "distancia histórica” como principio epistemológico, y aquellos más jóvenes que querían responder a las demandas sociales a través de su disciplina. Frente al panorama europeo, la discusión argentina era muy embrionaria. En aquellos tiempos y aun hoy, el problema de la relación entre el presente y el pasado reciente se traducía en términos de "memoria". Aún cuando siempre consideré a este concepto poco viable heurísticamente y de gran dispersión semántica, me ocupé por establecer precisiones teórico-metodológicas para acotar la utilización de la noción de memoria por parte de una Historia del Presente: el alcance social de la noción de "recuerdo" (¿qué es eso de recordar juntos?), el uso de categorías psicoanalíticas (¿la noción de trauma no transforma al historiador en terapeuta social?), la posibilidad de representar esos "pasados en conflicto" (¿cómo poner en palabras el horror vivido por los actores sin "sacralizar" su testimonio?) y las dimensiones éticas y políticas (¿qué rol, si lo hay, tiene el historiador en la construcción de una memoria justa?). Estos son ejemplos de preguntas que orientaron mis trabajos y que se plasmaron en dos libros y numerosos artículos. ${ }^{6}$ Referentes de esos trabajos fueron sin lugar a dudas R. Koselleck, P. Ricoeur, P. Nora, T. Todorov y todos los debates que se llevaron a cabo en el Institut d'Histoire du Temps Présent y al que visité en 2008. Asimismo, y paralelamente, veía grandes dificultades tanto en el contexto europeo como en el latinoamericano para determinar qué se entiende por "pasado reciente", "traumático", "que no pasa”, en fin, para delimitar el "presente", objeto de estudio, de una Historia del Presente. Dificultades que persisten hasta la actualidad, basta citar como ejemplo las últimas publicaciones de H. Rousso. Este debate que se daba al interior de la disciplina,

\footnotetext{
${ }^{6}$ Historia, narración y memoria. Los debates actuales en filosofía de la historia. 2005, Akal y como editora Pasados en conflicto. Representación, mito y memoria, 2009, Prometeo.
} 
coincidió con otro más amplio en el que el tiempo mismo comenzó a ser interrogado, es decir, el modo en el que son puestos en relación, en los diferentes presentes históricos, el pasado, el futuro y el presente (K. Pomian, F. Hartog, H.U. Gumbrecht). Muchos coincidimos en pensar que há cambiado la forma de experimentar el tiempo en Occidente y en aquellos países en que su influencia há sido indudable. Hay coincidências, a partir de F. Hartog, en llamar a esta nueva forma en que el presente es omnipresente, "presentismo", caracterizado por una aceleración. Creo que la Historia del Presente es un "sintoma" de este nuevo orden del tiempo, es escribir una historia del presente en el presente. Historizar el presente es considerar al presente como historia, es decir, mostrar la pura contingencia de lo humano, sin intentar encontrar su sentido en el pasado ni proyectarlo hacia el futuro. Pensar al presente en su desnudez y no como el mero punto de intersección entre pasado y futuro. $Y$ en esto creo que la historia como crítica juega un rol muy importante. En esta etapa he vuelto a mis lecturas de $M$. Foulcault, M. de Certau, H. White y D. Chakrabarty.

Tempo e Argumento: En el Brasil, durante algún tiempo, el campo de la Historia del Tiempo Presente fue blanco de críticas, sobre todo en cuanto a los procedimientos del hacer historiográfico que implica. ¿Cómo se constituyó ese campo del saber en Argentina? ¿Cuáles son los principales temas de investigación por los historiadores del "tiempo presente" en aquel país?

María Inés Mudrovcic: En Argentina, desde un primer momento, la progresiva aparición pública de la barbarie desplegada durante la dictadura (tortura, desapariciones, secuestro de niños) acercó la reflexión sobre el pasado reciente al debate generado en torno a los crímenes del nazismo. Ello hizo que una serie de problemas filosóficos, epistemológicos, historiográficos y éticos fueran extrapolados, en algunos casos, para el análisis del pasado reciente argentino. Sin embargo, en estos debates no siempre coincidieron los regímenes de la memoria con los regímenes de la historia. Los discursos en torno a la memoria se fueron construyendo de diversas 
maneras. En una primera etapa, éstos respondieron a las necesidades políticas del momento y estuvo en manos de actores sociales concretos y de organizaciones de DDHH. ${ }^{7}$ Aproximadamente, a mediados de los 90, si bien ya aparecían publicaciones de cientistas sociales, en las cuales los grandes ausentes fueron los historiadores, el espectro estuvo dominado por publicaciones periodísticas, literarias y testimoniales. ${ }^{8}$ Sin embargo, aunque los trabajos de cuño no historiográfico fueron los más abundantes, los historiadores también contribuyeron en esa reconstrucción (1983-1995). ${ }^{9}$ A partir de 1994 nuevas investigaciones y nuevos ensayos historiográficos aparecen y se multiplican a partir de $2000 .^{10}$ Por último, a partir del año 2000, los trabajos en torno a la memoria, y a la reconstrucción historiográfica del pasado reciente hicieron eclosión en diversas disciplinas (historia, sociología, literatura) motivando asimismo una reflexión filosófica, teórica y metodológica que vino a complementar desde diversos ángulos el espectro de las publicaciones, ya de por sí numerosas, para este entonces. ${ }^{11}$ Estas producciones sobre este pasado reciente podemos reorganizarlas a partir de cuatro contextos histórico-políticos diferentes. El primero se extiende a partir de 1983 y se relaciona con la etapa política

7 Entre los primeros trabajos que se editan en relación al pasado reciente en las primeras décadas de los ochenta pueden mencionarse, entre otros: Lanusse, A, 1977; Solari Irigoyen, H., 1983; Gasparini, J., 1988. Cf. también el texto probablemente más antiguo de un cientista social, Gillespie, R., 1982, (y su primera edición en castellano en 1987, Ed. Grijalbo). Asimismo, Ansaldi, W., 1986; Baschetti, R., 1988. Véase también la revista Punto de Vista; y algunos trabajos de índole periodística, v.g.: Verbitsky, H., 1985. etc.

${ }^{8}$ Cf. Caparross, M., y Anguita, C., 1997; Bonasso, M, 1997; Seoane, M., 1996; Grupo de Rosario Hacer la Historia, AA.VV. 1995; Dussel, I., Finocchio, S., Godjman, S., 1997; Cavarozzi, M., 1997; Revista Punto de Vista, AA.VV., 1999. Asimismo, en 1999 se creó la Comisión por la Memoria de La Plata a partir del descubrimiento de los Archivos de la D.I.P.B.A. En el marco de la Comisión se publica en agosto de 2000 la revista Puentes. En el primer número escriben Jelin, E.; Sábato, N.; Vezzetti, H., entre otros. Durante ese año se llevaba a cabo la segunda convocatoria a investigadores para trabajar sobre memorias de la represión.

${ }^{9}$ Del Barco, R. y otros, 1983; Cavarrozzi, M., 1983; Floria, C. y García Belsunce, C., 1988; Saenz Quesada, M., 1992, etc.

${ }^{10}$ Se pueden consultar, entre otros: Halperin Donghi, T., 1994; Romero, L. A., 1994; Quiroga, H. y Tcach, C. (comp.), 1996; Tcach, C., 2003; Novaro, M. y Palermo, V., 2003; Groppo, B. y Flier, P. (comp.), 2001; Ansaldi, W., 2004; Funes, A. G. (comp.), 2004.

${ }^{11}$ Toda la serie de libros Memorias de la Represión que expone los resultados de un programa desarrollado por el Panel Regional de América Latina del Social Science Research Council bajo la dirección de Jelin, E. y Degregori, C. es publicada entre 2002 y 2005. Cf. también Vezzetti, H., 2002; Bergero, A. y Reati, F., 1997; Asimismo, el tema está presente en proyectos y programas de investigación de Universidades Nacionales (La Plata, Litoral, Rosario, UBA, Comahue, Córdoba, etc.), postgrados como la Maestría de Historia y Memoria de la Universidad Nacional de la Plata, Jornadas y Congresos tanto de historia como de filosofía, etc. 
de la transición postdictatorial y que comienza con los decretos que ordenan el juicio a los ex comandantes de las Fuerzas Armadas y a los jefes de los partidos armados de izquierda. Es lo que se conoce como la "teoría de los dos demonios" y que fija un esquema interpretativo de clara ruptura con el pasado reciente. El segundo contexto corresponde al período iniciado por el gobierno menemista que decretó el indulto de los militares y de Firmenich, sin proponer, explícitamente, una narrativa alternativa del pasado reciente, pero que, sin embargo, puede ser llamado como el período de las autocríticas provenientes de ambos bandos, como así también el período del auge del boom memorial sobre el pasado reciente. Durante el tercer período, el gobierno de Néstor Kirchner intenta instalar una versión del pasado "romántica" de la militancia de los años setenta, borrando lo referido a la degradación de la vida pública y política vivida antes del golpe de estado. ${ }^{12}$ En esta etapa crecen los estudios que toman como eje interpretativo a la violencia política. El último período abarca desde 2006, año de la creación del CELTYV (Centro de Estudios Legales sobre el Terrorismo y sus Víctimas) hasta el actual gobierno, cuyo Secretario de DDHH recibe a los representantes de dicho Centro en 2016 y la Corte Suprema de Justicia declaró aplicable el beneficio del $2 \times 1^{13}$ para los delitos de lesa humanidad, fallo que fue revisado y limitado en el Congreso Nacional. El período actual se caracteriza por un retorno a la discusión de los $\mathrm{DDHH},{ }^{14}$ atravesados por la fuerte "grieta" política que vive el país, enmarcada, ahora, en las políticas neoliberales que se expanden en Latinoamérica. Asistimos también, en Argentina, a la creciente visibilización en el espacio público de lo que podemos denominar una “contramemoria” de los años 70 a través de actividades y publicaciones orientadas a instalar el tema de las víctimas de las organizaciones armadas.

En Argentina, como en otros países, el “pasado reciente” fue, en una primera etapa, muy cuestionado como objeto próprio de la historiográfia, de allí que los

\footnotetext{
12 Para los tres primeros períodos, cfr. Altamirano, C., "Pasado presente”, en C. Lida, H. Crespo y P. Yankelevich (comp.), Argentina, 1976, estudios en torno al Golpe de Estado, El Colegio de México, 2007.

${ }^{13}$ Es el beneficio que establece que transcurridos 2 años se debía computar doble cada día de prisión preventiva.

${ }^{14}$ El mes pasado se realizó en Buenos aires un encuentro titulado "Hacia una nueva agenda de los derechos humanos”, en el que participaron, entre otras personas, H. Vezzetti, G. Fernández Meijidi, C. Hilb.
} 
historiadores se incorporaran más tarde que otros cientistas sociales al estúdio de este campo. Los historiadores, hasta bien entrada la década de los noventa, miraban con recelo un campo en el que necesariamente quedan expuestos los compromisos ético-políticos. Para tomar un ejemplo y como un claro exponente de esta época es el historiador Luis Alberto Romero que en el libro Breve Historia Contemporánea de la Argentina publicado en 1994 y en un artículo ¿Para qué sirve la historia?" aparecido en el diario Clarín del 11/10/1996, defiende a "la distancia histórica" como garantía de la objetividad: "la historia termina hace cincuenta años; lo que sigue es política. La historia debe atenerse a los hechos, a lo realmente ocurrido; lo demás es filosofía" escribe en el diario. En aquella época los historiadores habían sido contemporáneos a los hechos vividos durante la Dictadura Militar, lo que los posicionaba fuertemente ante los acontecimentos ocurridos. En muchos casos, la escritura profesional y la experiência vivida formaban parte de una misma ecuación. Si bien Romero tiene una fuerte participación a comienzos de la democracia, consideraba epistemológicamente posible escindir historia y política. Durante ese período, los profesores de historia egresados de la mayoría de las Universidades Nacionales debían enfrentarse en el nivel medio con la enseñanza del pasado reciente argentino (obligatoria en la curricula), sin haber tenido una asignatura en sus planes de estudio dedicada a dicho campo disciplinar. Los más afortunados habrían cursado algún seminario. Ocuparse de la historia reciente era hacer “historia militante". Casi una década más tarde, jóvenes historiadores cuestionan fuertemente esta posición. El artículo “En torno a la interpretación de la historia reciente. Un debate con Luis Alberto Romero" de Andújar, D’ Antonio y Eidelman publicado en Lucha armada en la Argentina, $N^{\circ} 11$ (2008) constituye una clara defensa en pos de incorporar al pasado reciente en la agenda de los historiadores. El presente siglo nos encuentra con una singular situación. Por un lado, se vuelve a descalificar fuertemente a la Historia del Presente, la cara visible es nuevamente J.L. Romero quien, frente a la discusión pública que se dio a principios de este año acerca del número de desaparecidos en Argentina escribe, en el diario Clarin, una 
editorial volviendo al viejo concepto de "historia militante". ${ }^{15}$ Pero, por otro lado, hace poco más de cinco años asistimos a la entrada en escena de una nueva generación de profesionales de la historia que se han formado investigando temas del pasado reciente como único tema de especialización y sin haber sido sus contemporáneos. ${ }^{16}$ Podemos decir que en nuestro país, la historiografia del pasado reciente es un campo disciplinar en formación y creciente consolidación, aunque no solidamente constituído como es el caso, por ejemplo, de Francia. Aún cuando la acepción "pasado reciente" o “tiempo presente" no excluye, de por sí, ninguna temática, ${ }^{17}$ la producción historiográfica argentina se concentra, principalmente, en la violência política de los 70 que há recebido conceptualizaciones tan variadas que van desde "terrorismo de estado" hasta "genocidio". La periodización tampoco es unánime, mientras que en la mayoría de los programas de Historia Argentina de las Universidades Nacionales el período abarca hasta el comienzo de la Dictadura Militar, que queda sin estudiar; en algunos otros, muy pocos, se incorpora la década kirchnerista, es decir, directamente el ayer de nuestro presente. Asimismo, y de la mano de las nuevas generaciones de historiadores, comienzan a investigarse nuevos aspectos de la violência política, como es el tema de las mujeres, o las emociones o el exilio, por ejemplo. Son historias más cercanas a la historia social y la microhistoria, aunque lo político y lo económico no pierden su centralidad.

Tempo e Argumento: En términos historiográficos, ¿existen diferencias entre la Historia del Tiempo Presente producida en Argentina y en otros países latinoamericanos?

María Inés Mudrovcic: La Historia del Tiempo Presente, tal como la entiendo, está profundamente ligada a la vida política de cada país. Esta disciplina nace para intentar dar cuenta de la violência política en el marco de los estado-nación: desde

\footnotetext{
${ }^{15}$ Ver: https://www.clarin.com/opinion/historiadores-tiempo-presente_o_r1EboN-JZ.html.

${ }^{16}$ Formados por M. Franco, S. Jensen, F. Lorenz, F. Levin, entre otros.

${ }_{17}$ Paradójicamente, también nuevas generaciones de historiadores se ocupan del presente pero no son identificados como "historiadores del presente". Para citar un ejemplo, J. Perren, en el ámbito de mi Universidad, lidera un equipo en el que conviven los historiadores con los geógrafos, economistas y otros cientistas sociales que se ocupan de historizar la calidad de vida en Neuquén durante el período 1991-2010.
} 
dictaduras y genocídios a guerras civiles y regímenes totalitários. Y el tratamento de la Historia del Presente en Latinoamérica no es la excepción. Las formas de gestionar o de lidiar con ese pasado violento, a través no sólo de la Historia del Presente sino, también, por médio de medidas de justicia retroactiva, juicios histórico-políticos, instauración de conmemoraciones, de fechas y lugares, apropiaciones simbólicas de distinto tipo dependen, fundamentalmente, del presente político de cada país atraviese. El auge de la producción académica y no académica sobre el tema de la memoria y la proliferación de representaciones historiográficas y testimoniales sobre el pasado reciente en Argentina, por ejemplo, se debió, entre otras cuestiones, a que, en el caso argentino, el presente político necesitaba concebirse como "lo otro", como distinto, del pasado político dictatorial reciente. Diferente fue el caso de Chile en que los distintos "gobiernos de la concertación" pretendieron alejarse de ese pasado reciente dictatorial promovendo políticas ambíguas de la memoria que, en muchos casos, pueden ser leidas como políticas del silencio. O el caso de México, en el que situaciones más distantes en el tiempo son vividas también como pasado reciente, o como pasado que tiene continuidad en el presente. Tal es la representación de la Revolución Mexicana. En este caso, aunque el marco de sentido de "la transición a la democracia" comenzó a representarla como un ciclo cerrado o concluido, de todos modos perdura su sentido fundacional del presente. O el caso de Brasil, que desde 1995 a 2016 tuvieron presidentes que fueron víctimas de la dictadura y que aplicaron distintas políticas de estado que, adquieren gran relevancia para el pasado reciente, durante el gobierno de Dilma Rousseff. Es decir, cada país, planteó su agenda propia en relación al pasado reciente según fuese su presente político.

A pesar de que las resistencias a la Historia del Presente se replicaron también en la comunidad de los historiadores de Latinoamérica, el siglo XXI muestra una disciplina en crecimiento. Si bien en el Cono Sur, especialmente en Argentina, este proceso se realizó más rápido, paulatinamente los distintos países de la región fueron fortaleciendo su comunidad académica. No hay, sin embargo, marcos teóricos y metodológicos comunes que atraviesen a la disciplina. Las formas que adquieren las 
representaciones históricas del pasado reciente son múltiples: desde el relato intimista en el que prima la aproximación testimonial, hasta la presentación de un proceso atravesado por la tercera persona y/o cuadros estadísticos. No hay acuerdos ni en las periodizaciones ni tampoco en el uso de las fuentes o creación de archivos y existen, al interior de cada país, fuertes desacuerdos en relación a las categorías de análisis a usar para nombrar a los acontecimientos (¿dictadura? ¿régimen militar? ¿pronunciamiento? ¿guerra civil?, por ejemplo). Un fenómeno interesante que se ha visto en los últimos años y que tiende a consolidarse es la publicación de trabajos que reúnen investigaciones de diversos países de la región. Asoman allí, principios de estudios comparativos que se espera que se fortalezcan en el futuro. ${ }^{18}$

Tempo e Argumento: Desde tu punto de vista ¿la Historia del Tiempo Presente puede entenderse inequívocamente como el producto de un régimen de historicidad presentista?

María Inés Mudrovcic: Yo no digo que hay una relación inequívoca, pero sí, sin dudar, hay una correlación muy fuerte. El siglo XIX fue, tanto en Europa como en Latinoamérica, un siglo muy violento, pero sin embargo, los historiadores cuando se profesionalizan, se separan del presente. Si bien la inestabilidad y la violência política era parte de su presente, ellos se sentían comprometidos con la creación de un nuevo orden político: los estado-nación. Comandaba el futuro. Una historia del tiempo presente es impensable en un régimen de historicidade moderno que establece una ruptura clara entre el pasado y el presente. Esta forma de

\footnotetext{
${ }^{18}$ Me refiero a los trabajos de S. J. Stern, P. Winn, f. Lorenz, A. Marchesi, Batallas por la Memoria Histórica en el Cono Sur, Buenos Aires: Biblos, 2015 y de E. Allier y F. Lorenz, Las luchas por la memoria en américa latina. Historia reciente y violencia política, México: UNAM, 2015 o las publicaciones que se llevan a cabo en esta revista o F. Langue, "L'histoire du temps présent Amérique Latine, Caraïbes, Espagne”. Chemins de traverses mémoriels et Fabrique des médiations", De conserveries memorielles consacre a I'histoire du temps present dans les Mondes Iberiques, 20, 2017. Estos trabajos tienen como antecedentes a E. Jelin, (coordinadora) (2002-2006). Colección Memorias de la represión. Madrid: Siglo xxi Editores y C. Azevedo, d. rollemberg, p. Knauss, M. F. baptista Bicalho, S. Viz Quadrat, Cultura Política, memoria e historiografía, Río de Janeiro: FGV editora, 2009.
} 
experimentar el tiempo en el régimen de historicidade moderno se tradujo también en la forma en que la historia concibió al pasado, es decir, en un régimen historiográfico. El pasado histórico debía ser distante y diferente al presente; presuponía un tiempo irreversible que impedía que pueda repetirse o pueda ser tomado como ejemplo. Los historiadores creían que estas características los resguardaban de compromisos éticos o políticos com el presente y les aseguraban la objetividade en el conocimiento. Estudiar el presente, para ellos, era impensable. El presente se encontraba en los diários, pues era tarea de los periodistas recoger los acontecimentos que aún no habían tomado "formas definidas" y, por lo mismo, eran poco confiables. Los historiadores debían ser "observadores imparciales” y no inmiscuirse com los asuntos del presente.

Por el contrario, en el régimen de historicidade presentista, pasado y futuro son fagocitados por el presente. Hartog encuentra varias razones para que sea posible esta nueva experiência del tiempo: el crecimiento de la desocupación en masa, la caída progresiva del Estado de bienestar - construido en torno a las ideas de solidaridad y del que el mañana será mejor que el hoy -, el aumento de las demandas de una sociedad de consumo, en las que las innovaciones tecnológicas y la búsqueda de beneficios producen una obsolescencia cada vez más rápida de cosas y personas. La década de los 80 señala, sin duda, una inflexión para la historia y su régimen de temporalidad. Hace irrupción la historia del tiempo presente, poniendo en cuestión la difícil tensión entre el presente y la reconstrucción historiográfica del pasado reciente: en 1978 F. Bédarida crea el Institut d'histoire du temps présent (IHTP) que se inaugura en 1980 bajo su dirección, P. Nora se pone al frente de los estudios de la "Histoire du present" en l'Ecole des Hautes Etudes en Siences Sociales (EHESS), en 1988 se publica la revista Ayer de la Asociación de Historia Contemporánea.

Las 'catástrofes' o 'cataclismos' del siglo XX, interpelaron a la historia para hacerlas inteligibles. ¿Por qué no ocurrió lo mismo com la Revolución Francesa? ¿por qué no generó memorias “traumáticas"?. La Revolución Francesa, a pesar de las 
calamidades y los conflictos sufridos, no impidió un cierre del pasado y una apertura del futuro. Esto se vio reflejado en el orden de temporalidade moderno a través de los proyectos políticos arrojados al futuro y en la ruptura con el presente que dio lugar a que los acontecimientos ocurridos antes de 1789 se los pudiese tratar 'históricamente', es decir, como pasados cerrados. Sin embargo, la imprescriptibilidad jurídica de los crímenes cometidos en las guerras mundiales, los genocidios y los terrorismos de estado creó la contemporaneidad de los crímenes del pasado con las generaciones nacidas más tarde, aboliendo la distancia temporal que los separa. Fue este pasado que no termina de pasar, que se hace presente y se transforma en objeto de la historia del presente. Ahora bien, ¿es esta figura jurídica la única responsable de que el régimen de la memoria y el regiman de la historia colapsen en un orden temporal presentista?. Creo que la respuesta la debemos buscar en el "suelo" político. Así como en el orden temporal moderno había un mundo político por crear, en esta experiência presentista en los países occidentales, de vivir sumergidos en el pasado que se hace presente, se debe, entre otras cuestiones, a que las llamadas "grandes catástrofes del siglo XX", por más terribles que hayan podido ser, no lograron producir una ruptura en el plano político. La Revolución Francesa establece una brecha política entre un "Antiguo Régimen" y un presente nuevo. Quizás este centrarse mucho en un pasado reciente tenga que ver, en Occidente, con una frustración política. No olvidemos que las "grandes catástrofes" son hijas de esos estado-nación que eran la promesa política del siglo XIX. Sin duda alguna existe una relación entre experiencias del tiempo hegemónicas y la vida política que se pueden rastrear en prácticas como la historiografia.

Tempo e Argumento: ¿En qué medida un régimen de historicidad presentista cuestiona seriamente la noción de pasado histórico?

María Inés Mudrovcic: Lo cuestiona en la medida en que el presente del régimen presentista es indeterminado. Es un presente que no establece barreras claras con los muertos. El presente del presentismo occidental es totalmente diferente al 
presente que experimentaron las sociedades en el siglo XIX y que dio origen a la historia como disciplina y al "pasado histórico" como su objeto.

Durante el siglo XIX, primero en Francia y luego en el resto de Europa, se consolida una forma de experimentar el presente que ellos denominaron, “contemporaneidad". Ser contemporáneo era pertenecer al presente de las generaciones vivas que habitaban Europa y EEUU luego de la Revolución Francesa. El siglo XIX francés delimita su presente al establecer que la Revolución instaura una barrera con lo que se llamó “Antiguo Régimen”. La expresión Ancien Régime, conocida por los revolucionarios franceses y popularizada por Tocqueville y Taine, designa al "régimen feudal”, pasado que, para ellos, era muy próximo en el tiempo, pero que ambos consideran ya ido totalmente. Para Tocqueville, el sólo hecho de acuñar dicho nombre (Ancien Régime) abrió un “abismo" entre el pasado prerevolucionario y su futuro. La Revolución es la cesura política que separa al pasado de ese presente que se concibe como totalmente diferente y nuevo (neueste). La Francia que Tocqueville tiene ante sí pertenece a un presente que se experimenta como totalmente distinto del pasado. Es un presente que se distingue de su pasado como lo vivo de lo muerto. El presente contemporáneo es compartido por los vivos que miran a los muertos en la tumba del pasado. Ese pasado ya ido y muerto es el pasado feudal del Antiguo Régimen, que no "está muy distante, en años, de nuestros ojos, pero que la Revolución lo oculta”, según Tocqueville.

Esta idea de la novedad con que se experimenta el presente también es expresada por Taine en Les origines de la France Contemporaine. Escrita entre 1875 y 1893, la obra consta de cinco tomos organizados alrededor de tres temas, el Antiguo Régimen, la Revolución y el Régimen Moderno. ¿Qué es la Francia contemporánea? se pregunta Taine en el prefacio que antecede al volumen en el que se dedicará al Antiguo Régimen. Es la Francia que ha substituido, como un "insecto" en su metamorfosis, lo viejo por lo nuevo. La "criatura nueva”, la Francia contemporánea, es estable y completa pues "su antigua organización se ha disuelto". Francia se transforma en el locus de un continuo temporal que se interpreta como evolutivo a 
través de la metáfora del insecto que se desarrolla. Francia primero y Europa después, es decir, lo que desde 1890 iba a ser denominado como "Occidente", comienzan a constituirse en el estándar temporal a partir del cual se "miden" al resto de las naciones. Igual que para Tocqueville, la Revolución interpone una barrera infranqueable entre el pasado ya ido del Antiguo Régimen y la Francia contemporánea. Es un pasado que pertenece sólo a la "vieja” Francia. El presente contemporáneo se afirma excluyendo al pasado. Los muertos no pertenecen al presente.

Este sentimiento de ruptura con el pasado, que comparten no sólo los revolucionarios, sino, también, los reaccionarios se expresa hasta en la forma extrema de modificar el calendario. Esta manera que el "presente contemporáneo" tiene de oponerse al pasado, pasado que la Asamblea Nacional de Agosto de 1789 votó “destruir por completo", es totalmente nueva.

En el siglo XIX ser “contemporáneo" y ser "occidental” son dos caras de la misma moneda (cronopolítica y geopolítica). La contemporaneidad no sólo reconfigura al pasado, expulsándolo hacia "atrás" como “feudal y muerto"; sino que, también, reconfigura al presente diferenciando entre aquellos que no son mis contemporáneos por no compartir el mismo estadio político-cultural. No todos los que viven en el mismo tiempo, los coetáneos, son contemporáneos. La experiencia epocal de contemporaneidad nace, en el siglo XIX, a partir de la exclusión de aquellos que no comparten un mismo presente político. El presente separa al pasado como lo "otro": el "pasado histórico" es el resultado de esta operación diacrónica del régimen historicista moderno. Pero el presente contemporáneo también excluye a "otros" que viven en el mismo presente cronológico: los nocontemporáneos (los que no han alcanzado el desarrollo político de "Occidente") son los "otros" de esta operación sincrónica. Los contemporáneos son los que habitan en el estado moderno. El estado moderno se transforma en norma política que permite discriminar en el presente a los "otros", que son aquellos que viven bajo otras normas políticas (“los primitivos”). Pero también el estado moderno 
permite discriminar retrospectivamente. El "pasado histórico" sólo pertenece a los muertos que han contribuido a alcanzar el estado moderno. Hay pueblos "sin historia" que, si bien habitaron en el pasado, no fue en aquel pasado que contribuyó a alcanzar el presente contemporáneo.

La antropología y la historia se instauran como saberes a fines del siglo XVIII y se profesionalizan durante el siglo XIX. El presente contemporáneo crea dos tipos de alteridades temporales a los que corresponden dos géneros de saberes con sus respectivos objetos. El "salvaje" es el que se encuentra no sólo geográficamente fuera de Occidente sino que está atrasado en el tiempo, no es su contemporáneo, es un "primitivo". La distancia entre el "salvaje primitivo" y los "civilizados contemporáneos" es salvada por la antropología. La historia, por su parte, tendió un puente entre los muertos del pasado histórico y el presente que se comprendía como nuevo.

El conocimiento histórico se fundó en esta diferencia que el presente contemporáneo estableció con el pasado. En la medida en que el pasado es lo otro del presente, las vías de acceso al mismo debían cambiar. El testimonio y la tradición oral, ejemplos del conocimiento inmediato, son substituidos por los trazos que se transforman en fuentes. El pasado histórico no se le puede conocer directamente, el testigo ocular pierde la relevancia que había tenido desde Herodoto. Hasta la modernidad, el presente no difería del pasado sino que era el historiador que lo demarcaba, como dice Rousso, a partir de su propia subjetividad ('mientras tanto', 'en mi tiempo', 'antes', etc.). A partir del siglo XIX, la perspectiva que el historiador posee del pasado se independiza de aquellos que lo vivieron. El pasado es tan lo otro que es accesible sólo a través de las fuentes. El pasado así reconstruido es el “pasado histórico", contraparte del presente contemporáneo. La noción del principio de objetividad de la historia descansa sobre esta distinción entre pasado y presente. Sólo del pasado histórico puede el historiador pretender tener un conocimiento objetivo y para ello debe separarse de su propia contemporaneidad. El presente contemporáneo es el ámbito de la acción, de la política; el pasado 
histórico es el ámbito del conocimiento y del saber. Esta concepción de que el objeto de la historia es el "pasado historico" se extiende durante el siglo XX hasta los $80^{\prime}$ del siglo $\mathrm{XX}$, período durante el cual casi todos los historiadores profesionales coinciden en aceptar que la historia era una disciplina que investiga el pasado humano.

Todas estas características que fundaron las bases epistemológicas y metodológicas de la historia son cuestionadas por el presente del presentismo. El límite, la marca o la cesura entre vivos y muertos no están tan claras. Los muertos también pertenecen a este presente, salen de sus tumbas para reclamar justicia, recuerdo y un lugar en el espacio público. Este pasado que vive en el presente se conjuga en términos de memoria y viene a discutir los presupuestos temporales del "pasado histórico". Para Tocqueville, quien fue prácticamente contemporáneo a la Revolución Francesa, el pasado pre-revolucionario estaba muerto y acabado. A pesar de ser recuerdo de algunas de las generaciones que compartían su presente, ese pasado ya no le pertenecía, era un "pasado histórico". No ocurre lo mismo con el pasado reciente del presente del régimen presentista. Este último es un pasado que vive en el presente y que interpela a los historiadores. Los interpela de tal modo que lo incorporan como objeto de estudio pero, al hacerlo, deben repensar no sólo las bases epistemológicas de la disciplina sino, también, la función social de la historia. De allí que, en la actualidad, no sea tan fácil distinguir entre un "pasado histórico" y un "pasado práctico", como lo fue para Oakeshott en la década del 60, o sostener la cómoda dicotomía entre una "memoria" del pasado y un "saber" histórico o el divorcio entre ser historiador y ser un ciudadano políticamente comprometido. Lo que ha dejado al descubierto este presente del presentismo es la dimensión claramente crítica y, por lo tanto, ética, que posee la actividad historiadora. 
Universidade do Estado de Santa Catarina - UDESC Programa de Pós-Graduação em História - PPGH

Revista Tempo e Argumento Volume 09 - Número 21 - Ano 2017 tempoeargumento@gmail.com 